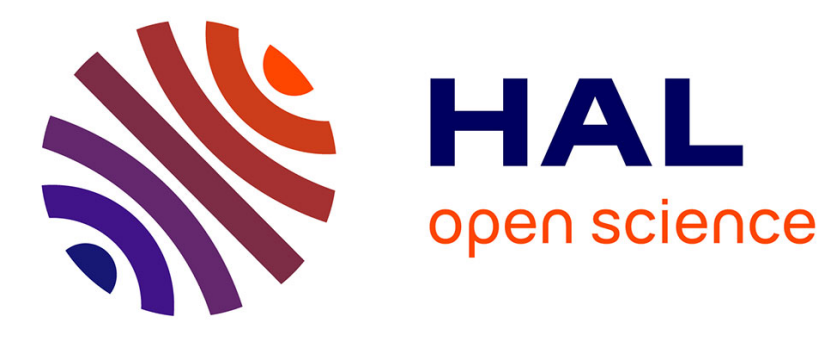

\title{
Modulating the Electrical Properties of Organic Heterojunction Devices Based On Phthalocyanines for Ambipolar Sensors
}

\author{
Seydou Ouedraogo, Rita Meunier-Prest, Abhishek Kumar, Mabinty \\ Bayo-Bangoura, Marcel Bouvet
}

\section{To cite this version:}

Seydou Ouedraogo, Rita Meunier-Prest, Abhishek Kumar, Mabinty Bayo-Bangoura, Marcel Bouvet. Modulating the Electrical Properties of Organic Heterojunction Devices Based On Phthalocyanines for Ambipolar Sensors. ACS Sensors, 2020, 5 (6), pp.1849-1857. 10.1021/acssensors.0c00877 . hal03028387

\section{HAL Id: hal-03028387 https://hal.science/hal-03028387}

Submitted on 27 Nov 2020

HAL is a multi-disciplinary open access archive for the deposit and dissemination of scientific research documents, whether they are published or not. The documents may come from teaching and research institutions in France or abroad, or from public or private research centers.
L'archive ouverte pluridisciplinaire HAL, est destinée au dépôt et à la diffusion de documents scientifiques de niveau recherche, publiés ou non, émanant des établissements d'enseignement et de recherche français ou étrangers, des laboratoires publics ou privés. 
Modulating the electrical properties of organic heterojunction devices based on phthalocyanines for ambipolar sensors.

Seydou Ouedraogo a, b*, Rita Meunier-Presta , Abhishek Kumara, Mabinty Bayo-Bangourab, Marcel Bouvet ${ }^{\mathrm{a} *}$

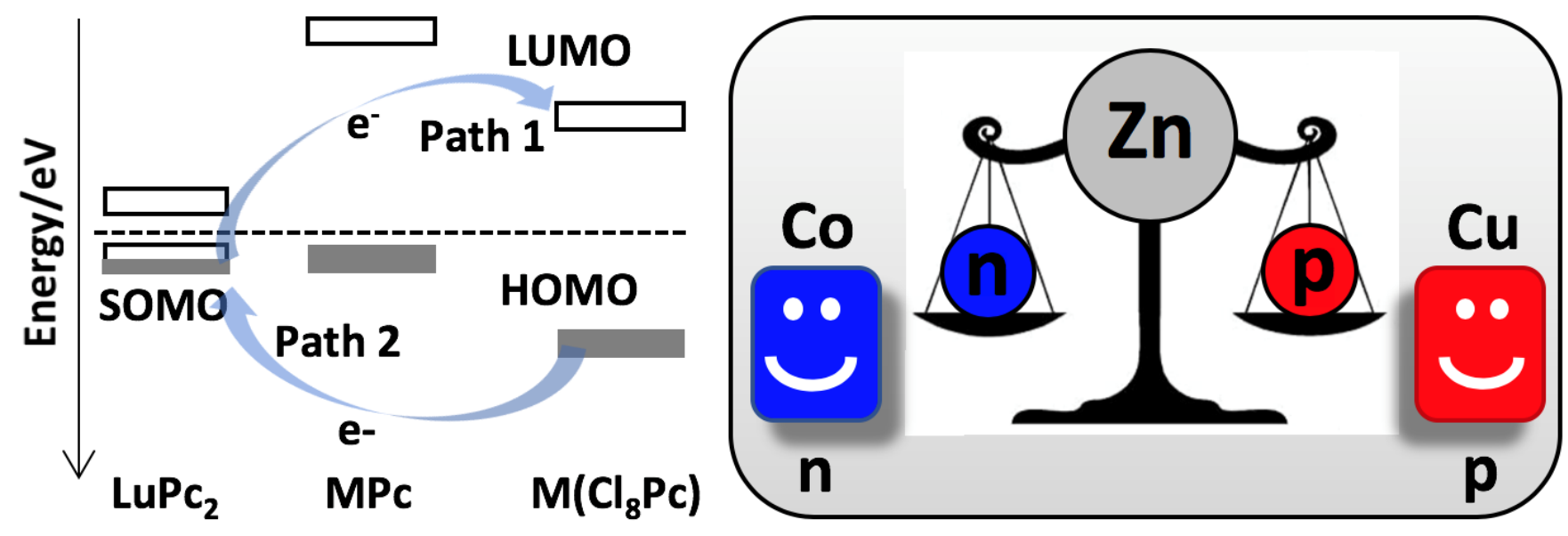




\title{
Modulating the electrical properties of organic heterojunction devices based on phthalocyanines for ambipolar sensors.
}

\author{
Seydou Ouedraogo ${ }^{\mathrm{a}}$ b*, Rita Meunier-Presta ${ }^{\mathrm{a}}$, Abhishek Kumara, Mabinty Bayo-Bangourab ${ }^{\mathrm{b}}$, Marcel \\ Bouveta*
}

\begin{abstract}
anstitut de Chimie Moléculaire de l'Université de Bourgogne (ICMUB), UMR CNRS 6302, Université Bourgogne Franche-Comté, 9 avenue Alain Savary, 21078 Dijon cedex, France. Tel: +33-380-396-086;

bLaboratoire de Chimie Moléculaire et de Matériaux, Université Joseph Ki-Zerbo, Ouagadougou, 03 BP 7021, Ouagadougou, Burkina Faso ;
\end{abstract}

KEYWORDS Molecular material, phthalocyanines, ambipolar materials, molecular semiconductor, relative humidity, ammonia sensor.

\begin{abstract}
Although ambipolar materials are highly studied in organic electronics, they are rarely used in gas sensors. In the present work, we studied ammonia sensing on organic heterojunctions in a bilayer configuration composed of octachlorinated metallophthalocyanines $\left(\mathrm{M}\left(\mathrm{Cl}_{8} \mathrm{Pc}\right) ; \mathrm{M}: \mathrm{Co}, \mathrm{Cu}\right.$ and $\left.\mathrm{Zn}\right)$ as a sublayer and lutetium bis-phthalocyanine $\left(\mathrm{LuPc}_{2}\right)$ as a top layer. Despite small effect of metal atom in $\mathrm{M}\left(\mathrm{Cl}_{8} \mathrm{Pc}\right)$ on the device current and the interfacial energy barrier, a strong effect on $\mathrm{NH}_{3}$ sensing behavior was found such that $\mathrm{Co}(\mathrm{Cl} 8 \mathrm{Pc}), \mathrm{Cu}\left(\mathrm{Cl}_{8} \mathrm{Pc}\right)$ and $\mathrm{Zn}\left(\mathrm{Cl}_{8} \mathrm{Pc}\right)$ based devices exhibited $\mathrm{n}$-type, p-type and ambipolar charge carrier transport, respectively. Variable carrier transport has been explained by charges hopping at the interface and subsequent heterojunctions formation. In particular, the ambipolar transport regime in $\mathrm{Zn}\left(\mathrm{Cl}_{8} \mathrm{Pc}\right)$ based device is triggered by the chemical doping from $\mathrm{NH}_{3}$ and water, when the device is exposed longer under $\mathrm{NH}_{3}$ at high humidity turning it n-type. Gas sensing studies performed in a wide concentration range of $\mathrm{NH}_{3}$ at a variable relative humidity (rh) exhibited very high sensitivity of these devices. The best performance is obtained with $\mathrm{Co}_{0}\left(\mathrm{Cl}_{8} \mathrm{Pc}\right)$ based device demonstrated by very high relative response $\left(13 \%\right.$ at $\left.10 \mathrm{ppm} \mathrm{NH}_{3}\right)$ and sensitivity $\left(1.47 \% \cdot \mathrm{ppm}^{-1}\right)$, sub-ppm limit of detection $(250 \mathrm{ppb})$ and negligible interference from $\mathrm{rh}$. Such superior sensing characteristics based on a new heterojunction device make it an ideal $\mathrm{NH}_{3}$ sensor for real application.
\end{abstract}

Organic molecular semiconducting materials have drawn wide research interests in developing electronic devices because of the fact that their electrical properties can be strongly tuned by the interaction with redox environment ${ }^{1}$. In fact such chemical doping is a prerequisite for using thin films of these materials in conductometric gas sensors where dynamics of charge carriers transport in the sensing layer determines the sensitivity towards target gases ${ }^{2}$. Although, majority of organic semiconductors are intrinsically ambipolar ${ }^{3}$, possessing electron $\left(\mathrm{e}^{-}\right)$and hole $\left(\mathrm{h}^{+}\right)$conduction channels, in ambient environment mainly unipolar transport behavior has been mainly observed, where numerous p-type and a few n-type materials transport properties have been exploited in gas sensing devices like organic field-effect transistors (OFETs) ${ }^{4}$ or organic heterojunctions ${ }^{5}$. However, there has been a growing endeavor to fabricate air-stable ambipolar devices for sensors applications to tap their advantages like dual mode operation (can work at positive as well as negative bias voltage), multiplex sensing at the same device platforms, which also helps miniaturizing the devices.

In the field of chemical sensors, only a few examples of ambipolar devices were reported, among which only two dealing with inorganic materials, namely molybdenum telluride $\left(\mathrm{MoTe}_{2}\right)^{6}$ and a bromide perovskite $\left(\mathrm{CsPBBr}_{3}\right)^{7}$ have shown bipolar carrier transport, but with rather poor performances. Organic molecular materials and particularly metal phthalocyanines (MPc) are being increasingly investigated to achieve the ambipolar transport regime ${ }^{8-10}$, and different strategies has been adopted. While using only one type of material, the design of organic semiconducting materials are focused on materials with small gaps between highest occupied molecular orbital (HOMO) and lowest unoccupied molecular orbital (LUMO), such that work function of the electrode could align with both energy levels for efficient injection of both charge carriers $\left(\mathrm{e}^{-}\right.$and $\left.\mathrm{h}^{+}\right)$. Lutetium bis-phthalocyanine $\left(\mathrm{LuPc}_{2}\right)$ is a typical example in which SOMO (Semi Occupied Molecular Orbital)and LUMO are separated by $0.5 \mathrm{eV}$ and led to the first reported OFET with $\mathrm{p}$ and $\mathrm{n}$ channels ${ }^{11}$. Beside $\mathrm{LuPc}_{2}$, ambipolar behavior of other families of materials including halogenated tetracenes or pentacenes and heteroatoms containing acenes, quinoidal quaterthiophene and tetracyanothienoquinoids and polyfluorene are worth mentioning 8,9 . However, in the ambient air conditions such behavior was suppressed because of oxygen and moisture. The other approaches of attaining an ambipolar 
behavior are by combining n-type and p-type semiconductors either by sequential bilayer deposition ${ }^{12,13}$ or by codeposition developing a blend ${ }^{14}$. The latter approach is not very favorable owing to the difficulty in morphologies control. Phthalocyanines-based bilayers, particularly fluorinated copper phthalocyanine combined with its unsubstituted counterpart, have been extensively investigated in OFET configuration and have demonstrated the ambipolar transport ${ }^{15,16}$. However, in the field of gas sensors only a few such devices have been reported.

Recently, Y. Chen et al. studied solution processed thin films transistors based on a series of bis(phthalocyaninato) $\left(\mathrm{EuPc}_{2}\right)$ and tris-(phthalocyaninato) $\left(\mathrm{Eu}_{2} \mathrm{Pc}_{3}\right)$ complexes exhibiting a current decrease under $\mathrm{NO}_{2}$, as for any n-type material and a current decrease under $\mathrm{NH}_{3}$, indicating a p-type behavior, therefore clearly exemplifying the ambipolar carriers transport ${ }^{17,18}$. Same group of authors also investigated the role of phenoxy and naphthoxy substitution in $\mathrm{Eu}_{2} \mathrm{Pc}_{3}$ based FET devices having a CuPc as underlayer in improving the carriers concentration ${ }^{19,20}$ and reported $\mathrm{h}^{+}$and $\mathrm{e}^{-}$mobility as $1.7 \mathrm{~cm}^{2} \mathrm{~V}^{-1} \mathrm{~s}^{-1}$ and $1.3 \mathrm{~cm}^{2} \mathrm{~V}^{-1} \mathrm{~s}^{-1}$, respectively, which translated into higher sensitivity toward target gases. One of us recently reported a solution processed bilayer OFET based on substituted copper phthalocyanines, which exhibited highly selective and sensitive ambipolar response towards ethanol, which was also dependent on individual position of $n$ or $p$ layer in the bilayer heterojunction ${ }^{21}$. Chemoresistors fabricated from triple decker phthalocyanine complexes bearing p-fluorophenoxy moieties, $\mathrm{Ln}_{2}\left[\mathrm{Pc}(\mathrm{OPhF})_{8}\right]_{3},(\mathrm{Ln}=\mathrm{Gd}, \mathrm{Tb})$ also exhibited ambipolar transport regime demonstrated by a current decrease under exposure to opposite chemical dopant gases $\mathrm{NO}_{2}$ and $\mathrm{NH}_{3}{ }^{22}$. However, it must be mentioned that all the materials leading to both $\mathrm{p}$ - and $\mathrm{n}$-channels in OFETs did not reveal ambipolar sensing behavior. Thus, a triple decker phthalocyanine complex bearing thiohexyl groups, $\mathrm{Eu}_{2}\left[\mathrm{Pc}(\mathrm{S}-\mathrm{hexyl})_{8}\right]_{3}$, behaved as a ntype material in chemoresistor configuration, with a current decrease under $\mathrm{NO}_{2}$, but was unsensitive to $\mathrm{NH}_{3}$ and $\mathrm{H}_{2} \mathrm{~S}^{23}$. Other than OFETs and chemoresistors, we have fabricated organic heterojunction type devices $^{5,24}$ also patented by us, consisting of a low conducting semiconductor as a sub-layer and high conducting semiconductor as a top layer and some of them have shown ambipolar characteristics. A heterojunction consisting of $\mathrm{Cu}\left(\mathrm{F}_{8} \mathrm{Pc}\right)$ as a sublayer and $\mathrm{LuPc}_{2}$ as a top layer, realized by vacuum sublimation, revealed high sensitivity towards ammonia and ambipolar carrier transport regime at high humidity ${ }^{25}$. Be- side these, a few gas sensors based on hybrid materials such as Zinc oxide/pentacene ${ }^{26}$ and diketopyrrole ${ }^{27}$ in FET device configuration have also exhibited ambipolar behavior. Despite high sensitivity of some of the above mentioned gas sensors, ambipolar materials are still little explored and further improvements especially in the field of new materials development, device design and sensors performance improvements are required.

Accordingly, in the present work, we have fabricated a novel organic heterojunction devices based on octachloro-metallophthalocyanines $\left(\mathrm{M}\left(\mathrm{Cl}_{8} \mathrm{Pc}\right)\right)$ as a sublayer and $\mathrm{LuPc}_{2}$ as a top layer (Scheme 1) and explored their ambipolar behavior while applying for ammonia sensing at different relative humidity ( $\mathrm{rh}$ ) values. Devices were fabricated by sequential deposition of $\mathrm{M}\left(\mathrm{Cl}_{8} \mathrm{Pc}\right)$ and $\mathrm{LuPc}_{2}$ in bilayer which were also characterized by optical spectroscopy to confirm the electronic structures of MPcs in the bilayer. Three different $\mathrm{M}\left(\mathrm{Cl}_{8} \mathrm{Pc}\right)(\mathrm{M}: \mathrm{Co}, \mathrm{Cu}$ and $\mathrm{Zn})$ were tested as sublayer in order to study the effect of metal atoms in phthalocyanine on the ammonia sensing behavior. The effect of different levels of relative humidity on ammonia sensing in all devices has been extensively studied. Finally, the analytical gas sensing parameters have been evaluated to demonstrate the practical applicability of the sensing devices.

\section{RESULTS AND DISCUSSION}

\section{Materials characterizations}

The molecular structure of $\mathrm{M}\left(\mathrm{Cl}_{8} \mathrm{Pc}\right) \mathrm{s}$ and $\mathrm{LuPc}_{2}$ has been shown in Figure $\mathrm{S} 1 . \mathrm{M}\left(\mathrm{Cl}_{8} \mathrm{Pc}\right)$ s and $\mathrm{LuPc}_{2}$ were synthesized in our lab and their formation were confirmed by mass spectroscopy measurements. Different organic heterojunctions studied here are named as $\mathrm{LuPc}_{2} / \mathbf{1}, \mathrm{LuPc}_{2} / \mathbf{2}, \mathrm{LuPc}_{2} / \mathbf{3}$ and $\mathrm{LuPc}_{2} / \mathbf{4}$ where $\mathrm{Zn}\left(\mathrm{Cl}_{8} \mathrm{Pc}\right), \mathrm{Co}\left(\mathrm{Cl}_{8} \mathrm{Pc}\right), \mathrm{Cu}\left(\mathrm{Cl}_{8} \mathrm{Pc}\right)$ and $\mathrm{CoPc}$ represent 1, 2, 3 and 4 respectively. To further evaluate the structure, purity and the robustness of these materials under high temperature vacuum sublimation, deposited thin films bilayers were characterized by UV-Visible electronic absorption and Raman spectroscopies. Moreover, such measurements can also give information about any possible electronic interaction taking place between two layers of phthalocyanine. Figure 1 shows the comparison of electronic absorption spectra of $\mathrm{LuPc}_{2}, \mathrm{Zn}\left(\mathrm{Cl}_{8} \mathrm{Pc}\right)$ and $\mathrm{LuPc}_{2} / \mathrm{Zn}\left(\mathrm{Cl}_{8} \mathrm{Pc}\right)$ bilayer, depicting superimposition of the typical phthalocyanine $\mathrm{Q}$ absorption bands of $\mathrm{LuPc}_{2}$ and $\mathrm{Zn}\left(\mathrm{Cl}_{8} \mathrm{Pc}\right)$, which is also indicative of absence of significant 
charge transfer in the bilayer. The maximum wavelength, at $675 \mathrm{~nm}$, belongs to $\mathrm{LuPc}_{2}$ and the shoulders at 645 and $695 \mathrm{~nm}$ belong to $\mathrm{Zn}\left(\mathrm{Cl}_{8} \mathrm{Pc}\right)$. The weak band below $500 \mathrm{~nm}$ corresponds to a transition of a filled orbital towards the semi-occupied orbital of $\mathrm{LuPc}_{2}{ }^{28,29}$. The same type of spectrum was observed for $\mathrm{LuPc}_{2} / 2$ and $\mathrm{LuPc}_{2} / 3$.

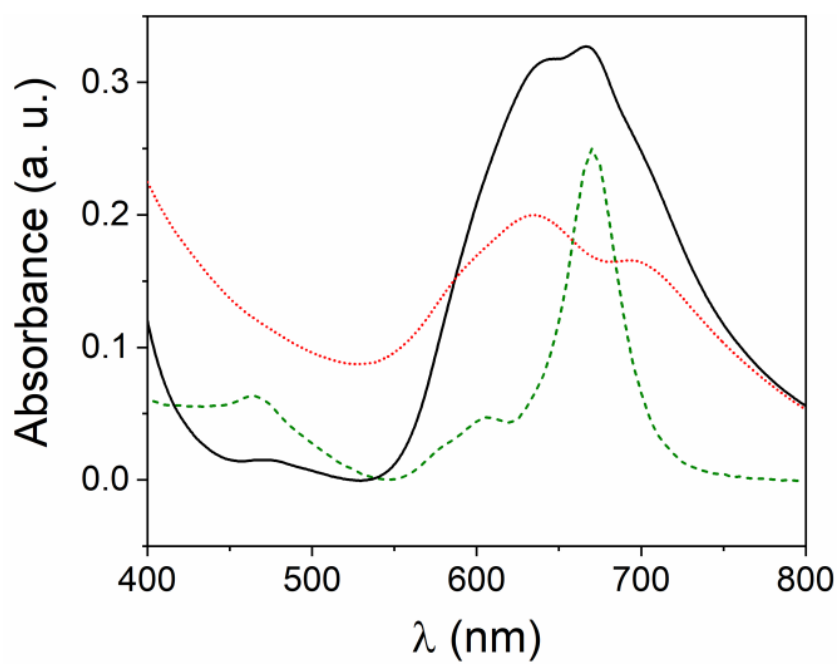

Figure 1. UV-vis electronic absorption spectra of a film of $\mathrm{LuPc}_{2} / \mathbf{1}$ on glass, compared to those of $\mathrm{LuPc}_{2}$ (green dashed line) and $\mathbf{1}$ (red dotted line).

Raman spectra of the heterojunctions are compared to those of powders of 1, 2, $\mathbf{3}$ and $\mathrm{LuPc}_{2}$ (Table S1). They show peaks that can be directly attributed to the two layers, as shown by the superimposition of the spectra of $\mathbf{1}, \mathrm{LuPc}_{2}$ and the $\mathrm{LuPc}_{2} / \mathbf{1}$ heterojunction (Fig. 2), particularly in the range $1350-1650 \mathrm{~cm}^{-1}$. Thus, for the $\mathrm{LuPc}_{2} / \mathbf{1}$ device, peaks can be directly attributed to the $\mathrm{LuPc}_{2}$ layer ${ }^{30}$, in particular the peaks at $578 \mathrm{~cm}^{-1}$ corresponding to $\mathrm{Pc}$ breathing, at $783 \mathrm{~cm}^{-1}$ to $\mathrm{C}=\mathrm{N}$ aza breathing, at $1122 \mathrm{~cm}^{-1}$ to $\mathrm{C}-\mathrm{H}$ bending, at $1158 \mathrm{~cm}^{-1}$ to pyrrole breathing and the one at $1333 \mathrm{~cm}^{-1}$ to $\mathrm{C}=\mathrm{C}$ pyrrole and benzene stretchings. The peak at $1512 \mathrm{~cm}^{-}$ ${ }^{1}$ corresponds to $\mathrm{C}=\mathrm{C}$ pyrrole stretching and coupling of pyrrole and aza stretching. Other peaks can be assigned to the sublayer, at 659, 815, 861, 1048, 1394 and $1574 \mathrm{~cm}^{-1}$. Additionally, peaks are common to both materials, among which the most intense are the peaks at $682 \mathrm{~cm}^{-1}$ (Pc breathing), $1176 \mathrm{~cm}^{1}$ (C-H bending), 1409 and $1512 \mathrm{~cm}^{-1}$ (C-H bending) and $1599 \mathrm{~cm}^{-}$ ${ }^{1}$ (benzene stretching). These results also confirm that the vacuum sublimation of chlorophthalocyanines and $\mathrm{LuPc}_{2}$ was achieved correctly without decomposing the macrocycle ring of MPcs.
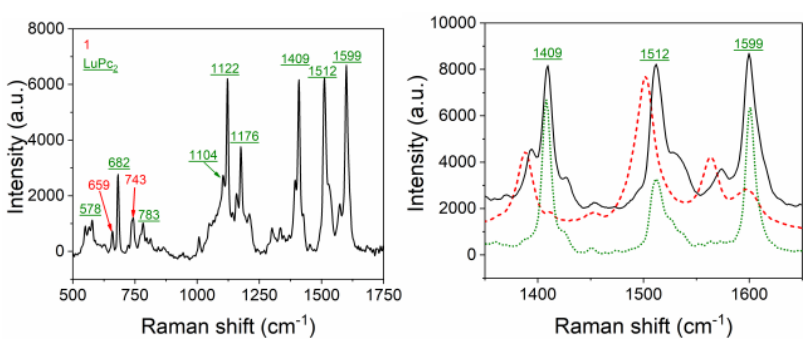

Figure 2. (left) Raman spectrum of a $\mathrm{LuPc}_{2} / \mathbf{1}$ heterojunction; the assignment of peaks characteristic of both materials is given; (right) superimposition of spectra of $\mathbf{1}$ (solid line), $\mathrm{LuPc}_{2}$ (dotted line) and $\mathrm{LuPc}_{2} / \mathbf{1}$ (dashed line) in the range 1350-1650 cm-1; the Raman shift value of the most intense peaks of the two components is given.

\section{Electrical properties}

Resistors made from 1, $\mathbf{2}$ and $\mathbf{3}$ exhibited linear current-voltage $(\mathrm{I}(\mathrm{V}))$ characteristics, with a very high resistivity, estimated to be ca. $10^{9}-10^{10} \Omega . c m$. They were subsequently adapted in a heterojunctions configuration as shown in Scheme 1 as a $50 \mathrm{~nm}$ thick sublayer of $\mathrm{M}\left(\mathrm{Cl}_{8} \mathrm{Pc}\right)$ covered with $50 \mathrm{~nm}$ of $\mathrm{LuPc}_{2}$ as a top layer such that electrodes remain inside the sublayer. The geometry of the heterojunction is original and is different from conventional OFET, since the poor conducting material is in contact with the electrodes but not the more conducting material. We patented this type of heterojunction and used it with different sublayers ${ }^{5,31-33}$.

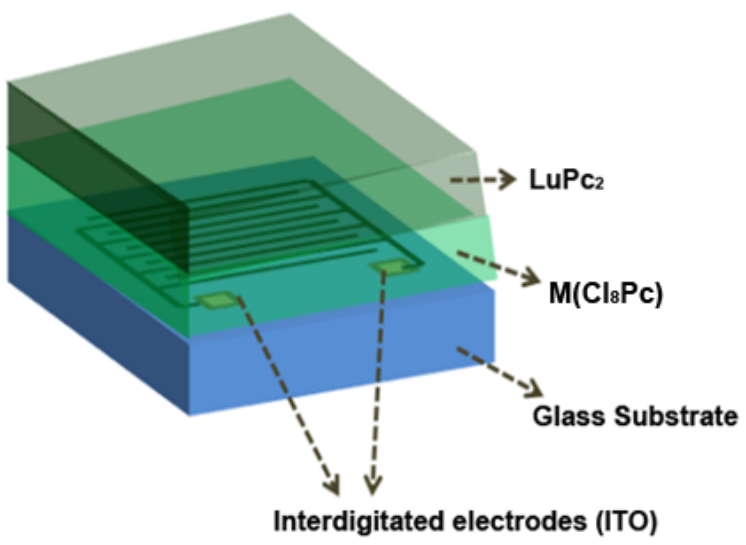

Scheme 1. Representation of the organic heterojunction devices configuration.

The I(V) characteristics of the heterojunction devices as shown in Figure 3 revealed a nonlinear, but symmetrical characteristics, with a current value at $+10 \mathrm{~V}$ of ca. 13, 6.3 and $3 \mu \mathrm{A}$ for $\mathrm{LuPc}_{2} / \mathbf{1}, \mathrm{LuPc}_{2} / \mathbf{2}$ and 
$\mathrm{LuPc}_{2} / \mathbf{3}$, respectively. The conductivity values also remained in the same order of magnitude for the three devices. The non-linearity in the I(V) curves confirms the non-ohmic contact between $\mathrm{LuPc}_{2}$ and $\mathrm{M}\left(\mathrm{Cl}_{8} \mathrm{Pc}\right)$ and the existence of an interfacial energy barrier between the two materials or/and between the electrodes and the sublayers. The interfacial energy barriers can be quantified by a threshold voltage obtained by the $\mathrm{x}$-intercept of the linear part of curves, at high bias values. For $\mathrm{LuPc}_{2} / \mathbf{1}$, this threshold voltage is 1.5 $\mathrm{V}$, i.e. the lowest energy barrier in the series, against $1.9 \mathrm{~V}$ and $2.75 \mathrm{~V}$ for $\mathrm{LuPc}_{2} / 2$ and $\mathrm{LuPc}_{2} / 3$, respectively. Thus, lower is the threshold value higher is the current at $+10 \mathrm{~V}$. Such low variations in threshold voltage are consistent with lesser impact of central metal atom in phthalocyanine complex on its electronic properties ${ }^{34,35}$ like HOMO and LUMO levels alignment. Nonetheless, it is evident that charge injection is relatively easier in $\mathrm{Zn}\left(\mathrm{Cl}_{8} \mathrm{Pc}\right)$ based devices while it is comparatively difficult on $\mathrm{Cu}\left(\mathrm{Cl}_{8} \mathrm{Pc}\right)$ based devices. On the other hand, heterojunction effect, comprising opposite charges alignment at the interface will be weaker in $\mathrm{Zn}\left(\mathrm{Cl}_{8} \mathrm{Pc}\right)$ and stronger in $\mathrm{Cu}\left(\mathrm{Cl}_{8} \mathrm{Pc}\right)$.

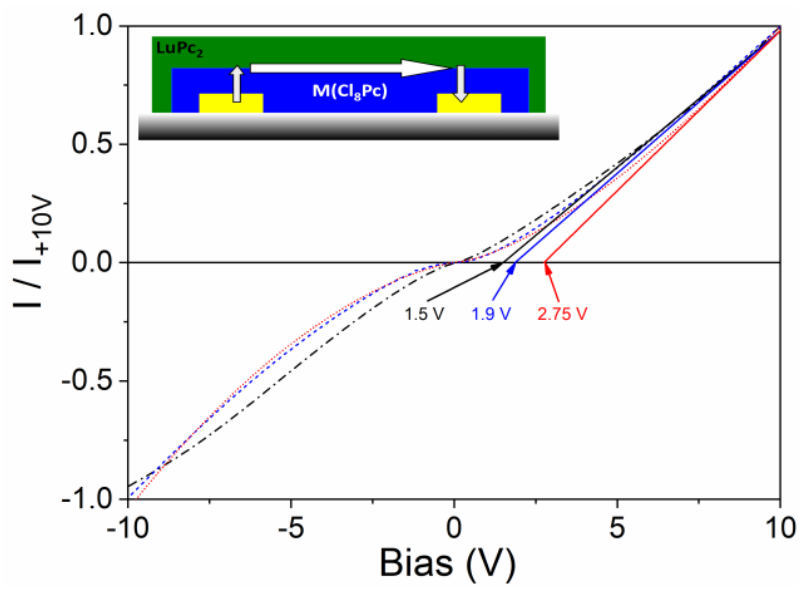

Figure 3. I(V) characteristics of a $\mathrm{LuPc}_{2} / \mathbf{1}$ (black dash dot), $\mathrm{LuPc}_{2} / 2$ (blue short dash) and $\mathrm{LuPc}_{2} / 3$ (red dot) heterojunctions; the value of the threshold voltage is given for the heterojunction. A schematic view of the heterojunctions is given in the inset; the arrows indicate the main path for charges.

\section{Ammonia Sensing properties}

The response of the devices towards ammonia vapor was studied by submitting to a $90 \mathrm{ppm}$ of $\mathrm{NH}_{3}$ for 10 min exposure cycle followed by 40 min recovery cycle under clean air devoid of ammonia and the associated variations in the current has been depicted in Figure 4. A contrasting behavior in the device current variations was observed as a function of metal atom as well as chloro-substitution in the sub-layer phthalocyanine exhibited by current increase for $\mathrm{Co}\left(\mathrm{Cl}_{8} \mathrm{Pc}\right)$ while a current decrease for $\mathrm{Zn}\left(\mathrm{Cl}_{8} \mathrm{Pc}\right), \mathrm{Cu}\left(\mathrm{Cl}_{8} \mathrm{Pc}\right)$ and $\mathrm{CoPc}$ based devices under ammonia and vice-versa under clean air. Considering the electron donating nature of $\mathrm{NH}_{3}$, seminconducting polarity of $\mathrm{LuPc}_{2} / \mathrm{Co}\left(\mathrm{Cl}_{8} \mathrm{Pc}\right)$ heterojunction device is of n-type while others exhibit p-type behavior, which also corresponds to the sublayer semiconducting nature ${ }^{5}$. The effect of chlorosubstitution in CoPc on obtaining opposite $\mathrm{NH}_{3}$ response is also clearly depicted in the $\mathrm{I}(\mathrm{t})$ curves in Figure $4 \mathrm{~b}$ and $4 \mathrm{~d}$. The current variations under $\mathrm{NH}_{3}$ exposure results from the chemical doping of electrons from $\mathrm{NH}_{3}$ into the semiconducting bilayer, altering the charge carrier concentrations and finally the device current.
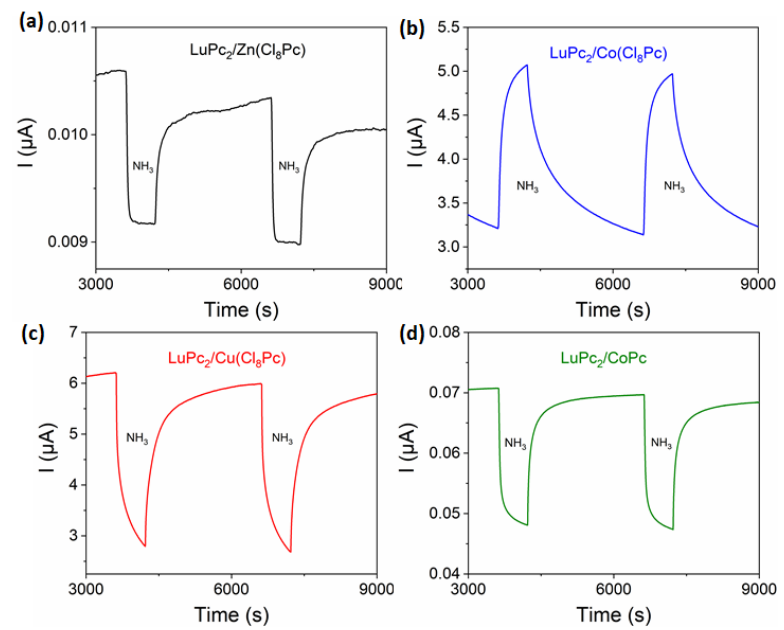

Figure 4. Current variation as a function of time of $\mathrm{LuPc}_{2} / \mathbf{X}$ heterojunctions, $\mathbf{X}=\mathbf{1}$ (a), $\mathbf{2}$ (b), $\mathbf{3}$ (c) and $\mathbf{4}$ (d) exposed to 90 ppm $\mathrm{NH}_{3}$ for 10 min-long periods separated by $40 \mathrm{~min}$ long rest periods in synthetic air, with $30 \% \mathrm{rh}$, at a bias of 1 $\mathrm{V}$.

It is worth noting that $\mathrm{LuPc}_{2}$ and MPc (M: Cu, Zn and Co) are p-type semiconductors in air and their relative energy bands position has been shown in Scheme-2a depicting HOMO and LUMO levels of MPcs and SOMO and LUMO of $\mathrm{LuPc}_{2}{ }^{36-38}$. Substitution by a strong electron withdrawing group such as halides does not change the HOMO-LUMO gap but only shifts the two bands towards the lower energy ${ }^{37,39,40}$. Accordingly the HOMO-LUMO levels of $\mathrm{M}\left(\mathrm{Cl}_{8} \mathrm{Pc}\right)$ will be shifted to the more negative energy as depicted in Scheme 2a and will have higher workfunction $(\Phi)$ from their MPc counterparts. Depending on the workfunction of 
$\mathrm{M}\left(\mathrm{Cl}_{8} \mathrm{Pc}\right)$, there can be two pathways of $\mathrm{e}^{-}$hopping at the interface, either from $\mathrm{HOMO}$ of $\mathrm{M}\left(\mathrm{Cl}_{8} \mathrm{Pc}\right)$ to SOMO of $\mathrm{LuPc}_{2}$ if $\Phi_{\mathrm{LuPc} 2}>\Phi_{\mathrm{M}(\mathrm{Cl} / 8 \mathrm{Pc})}$, or from SOMO of $\mathrm{LuPc}_{2}$ to LUMO of $\mathrm{M}\left(\mathrm{Cl}_{8} \mathrm{Pc}\right)$ if $\Phi_{\mathrm{LuPc} 2}<\Phi_{\mathrm{M}(\mathrm{Cl} l 8 \mathrm{Pc})}$. The $\Phi_{\mathrm{Zn}(\mathrm{Cl} 18 \mathrm{Pc})}$ of a thin film is $5.2 \mathrm{eV}$ (HOMO: $6.41 \mathrm{eV}$, LUMO: $4.30 \mathrm{eV}$ ) ${ }^{41}$, which is almost similar to $\Phi_{\mathrm{LuPc} 2}{ }^{42}$. Although there is a little influence of central metal in MPc on its electronic properties, a small variation in electronic properties can reverse the charge hopping pathways as shown in the scheme $2 \mathrm{a}$. It has been reported previously that among the MPcs, CoPc has the highest electron affinity while CuPc has the lowest and $\mathrm{ZnPc}$ has the intermediate values between two ${ }^{35}$. Therefore, electron hopping will take place via path 1 in $\mathrm{LuPc}_{2} / 2$ devices $\left(\Phi_{\mathrm{LuPc} 2}<\Phi_{\mathrm{Co}(\mathrm{Cl} 8 \mathrm{PC})}\right)$, while through path 2 in $\mathrm{LuPc}_{2} / \mathbf{1}$ and $\mathrm{LuPc}_{2} / \mathbf{3}\left(\Phi_{\mathrm{LuPc} 2}>\Phi_{\mathrm{Cu}(\mathrm{Cl} 8 \mathrm{Pc})}\right)$ under an external bias. For $\mathrm{LuPc}_{2} / \mathbf{4}$ device $\left(\Phi_{\mathrm{LuPc} 2}>\Phi_{\mathrm{CoPc}}\right)$, e- hopping from HOMO of CoPc to SOMO of $\mathrm{LuPc}_{2}$ will be a preferred path ${ }^{43}$.

As described interfacial charges hopping ultimately results in the formation of organic heterojunctions also described previously ${ }^{44}$. It takes the form of accumulation heterojunction (scheme 2c) for $\mathrm{LuPc}_{2} / \mathbf{2}$ device because of $\mathrm{e}^{-}$hopping in $\mathrm{Co}\left(\mathrm{Cl}_{8} \mathrm{Pc}\right)$ sublayer, which creates equal number of $\mathrm{h}^{+}$in $\mathrm{LuPc}_{2}$ top layer, while hole accumulation/depletion heterojunction (scheme 2b) for $\mathrm{LuPc}_{2} / \mathbf{1}$ and $\mathrm{LuPc}_{2} / \mathbf{3}$ devices resulting from $\mathrm{h}^{+}$ accumulation in $\mathrm{Cu}\left(\mathrm{Cl}_{8} \mathrm{Pc}\right)$ or $\mathrm{Zn}\left(\mathrm{Cl}_{8} \mathrm{Pc}\right)$ and $\mathrm{h}^{+}$depletion in $\mathrm{LuPc}_{2}$, also illustrated in scheme $2 \mathrm{~b}$. It must be noted that during the device operation, device current will be determined by the $\mathrm{e}^{-}$or $\mathrm{h}^{+}$carriers present in the sublayer since electrodes are embedded in it.

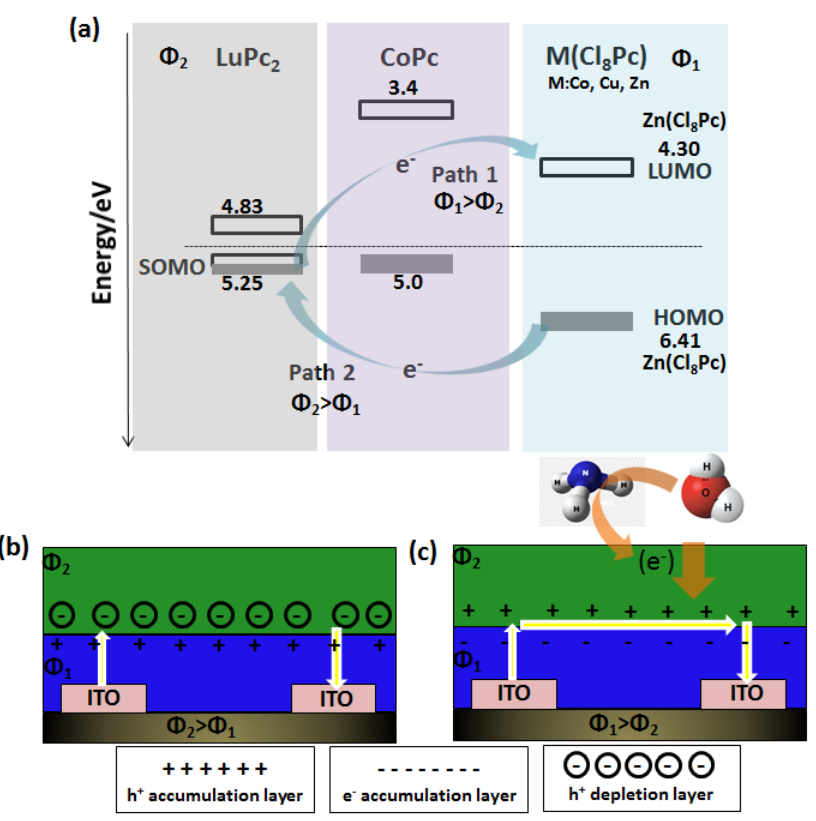

Scheme 2. Charges hopping at the bilayer interface depending on workfunction of each semiconductor in the heterojunction (a) and alignments of charges at the heterojunction if $\Phi_{\mathrm{LuPc} 2}>\Phi_{\mathrm{M}(\mathrm{Cl} 8 \mathrm{Pc})}$ (b) and if $\Phi_{\mathrm{LuPc} 2}<\Phi_{\mathrm{M}(\mathrm{Cl} \mathrm{PP})}(\mathrm{c})$.

During the $\mathrm{NH}_{3}$ exposure, it will act as a chemical dopant of $\mathrm{e}^{-}$in the top $\mathrm{LuPc}_{2}$ layer resulting in the decrease of its electron affinity because of e- filling in its SOMO orbital and consequently it will facilitate the $\mathrm{e}$ hopping through path 1 and will suppress the e- hopping through path 2 . Such charge redistribution upon $\mathrm{NH}_{3}$ exposure results in the enhanced e- accumulation in $\mathrm{LuPc}_{2} / \mathbf{2}$ while reduced $\mathrm{h}^{+}$accumulation in $\mathrm{LuPc}_{2} / \mathbf{1}$ and $\mathrm{LuPc}_{2} / \mathbf{3}$ sublayer. Therefore, a current increase takes place in $\mathrm{LuPc}_{2} / 2$ while a current decrease is noticed for $\mathrm{LuPc}_{2} / \mathbf{1}$ and $\mathrm{LuPc}_{2} / \mathbf{3}$ devices upon $\mathrm{NH}_{3}$ exposure while opposite trends during recovery steps (Fig. 4). After 10 min exposure to $90 \mathrm{ppm}$ of $\mathrm{NH}_{3}$, the relative response, (RR), defined, as $\mathrm{RR}(\%)=$ $\frac{I_{f}-I_{0}}{I_{0}} \times 100$, is ca. $+58 \%$ for $\mathrm{LuPc}_{2} / 2$ against $-55 \%$ for $\mathrm{LuPc}_{2} / \mathbf{3},-32 \%$ for $\mathrm{LuPc}_{2} / \mathbf{4}$ and only $-13 \%$ for $\mathrm{LuPc}_{2} / \mathbf{1}$.

It is also worth noting that, in the same experimental conditions, $\mathrm{LuPc}_{2}$ resistors exhibit a very bad response to ammonia, in particular exhibiting low RR and high drift of the baseline ${ }^{33}$. Hence, the key role of the bilayer device configuration and use of an octachlorinated phthalocyanine as a sublayer is improving the response towards $\mathrm{NH}_{3}$ is clearly established.

\section{Humidity effect}

The response of the devices towards $\mathrm{NH}_{3}$ was also studied at different rh values, in the range $30-70 \%$, during short exposure/recovery cycles (1 min / 4 min), at a constant $\mathrm{NH}_{3}$ concentration, namely $30 \mathrm{ppm}$ (Fig. 5). This humidity range was chosen because in most of the practical applications such as in industries or in air quality stations, gas sensors operate within this broad humidity range. For, $\mathrm{LuPc}_{2} / 2$, the humidity decrease induced only a slight drift of the baseline (current value at the starting of each exposure period), by $4 \%$ from $70 \%$ rh to $30 \%$ rh. This variation is strongly lower than the response to $30 \mathrm{ppm} \mathrm{NH}_{3}$. For $\mathrm{LuPc}_{2} / \mathbf{3}$, the sensitivity to humidity was higher, such that a change in $+39 \%$ and $+23 \%$ in RR is noted for a rh variation from $70 \%$ to $10 \%$ and between $50 \%$ and $10 \%$, respectively. Moreover, the absolute value of the response to $\mathrm{NH}_{3}$ varies with the rh value. Interestingly, for $\mathrm{LuPc}_{2} / 3$, RR increases from $12.5 \%$ to $19.5 \%$ when the rh value increases from $30 \%$ to $70 \%$ rh, while it decreases for $\mathrm{LuPc}_{2} / \mathbf{2}$, from $29 \%$ to $18 \%$ when the rh 
value increases in the same range. This last behavior is rather rare, because, generally, in chemiresistors, an increase of the humidity induces an easier adsorption of $\mathrm{NH}_{3}$ molecules, then a higher response to $\mathrm{NH}_{3}$. This can be attributed to competitive sorption kinetics of $\mathrm{H}_{2} \mathrm{O}$ and $\mathrm{NH}_{3}$ at higher rh, suppressing the electronic effects of the gas molecules ${ }^{45}$. For n-type heterojunction devices, less adsorption of $\mathrm{NH}_{3}$ results in smaller electron transfer from $\mathrm{LuPc}_{2}$ top layer to the $\mathrm{Co}\left(\mathrm{Cl}_{8} \mathrm{Pc}\right)$ sublayer, resulting in decrease in response of the device at higher rh.

The behavior of $\mathrm{LuPc}_{2} / \mathbf{1}$ is dramatically different. Indeed, the baseline increases by $38 \%$ from $70 \%$ rh to $30 \%$ rh, with a rather good reversibility when coming back to $70 \%$ rh. This variation is higher than the response to $30 \mathrm{ppm} \mathrm{NH}_{3}$. It means that humidity is a strong interferent of $\mathrm{NH}_{3}$ only for this particular device. Such behavior can be explained by the e- doping by water molecules in the $\mathrm{LuPc}_{2}$ top layer, and accordingly the $\mathrm{e}^{-}$hopping from the $\mathrm{HOMO}$ of $\mathrm{Zn}\left(\mathrm{Cl}_{8} \mathrm{Pc}\right)$ will be affected. Another phenomenon is still more surprising with this sample: The response to $\mathrm{NH}_{3}$, negative at high rh values turns positive at lower rh values. It means that this heterojunction behaves towards $\mathrm{NH}_{3}$ as a p-type or a n-type device, depending on the humidity contained in the atmosphere. $\mathrm{LuPc}_{2} / \mathbf{1}$ behaves as a p-type behavior at high rh values and as a n-type at low humidity, which also clearly demonstrates the ambipolar transport regime in this device. It means that water molecules are not only doping $\mathrm{e}$ in the $\mathrm{LuPc}_{2}$ top layer but also slowly diffusing in the sublayer, and subsequent $\mathrm{e}^{-}$doping in the sublayer reduces its electron affinity and inverts the charge hopping pathways at the interface, thereby transforming a hole accumulation/depletion heterojunction into an accumulation heterojunction with opposite device polarity towards $\mathrm{NH}_{3}$.

For $\mathrm{LuPc}_{2} / \mathbf{1}$, the response to $\mathrm{NH}_{3}$ appears very small compared to the other heterojunctions, with a RR value at $30 \mathrm{ppm}$ of $+2 \%$ at $30 \% \mathrm{rh}$ and $-1 \%$ at $70 \% \mathrm{rh}$, but only -0.5 at $50 \%$ rh. This unique behavior can be explained only by the ambipolar character of $\mathrm{Zn}\left(\mathrm{Cl}_{8} \mathrm{Pc}\right)$, as we previously reported for $\mathrm{Cu}\left(\mathrm{F}_{8} \mathrm{Pc}\right){ }^{25}$. At a first glance, the response of this sensor to $\mathrm{NH}_{3}$ seems quite bad, since it is positive or negative depending on the rh value. However, it can be taken advantage of such a behavior, the key point being the capability of the operator to control the change of electronic behavior, from p-type to n-type and vice versa, as we will see hereafter.

Actually, we were able to get the $\mathrm{LuPc}_{2} / \mathbf{1}$ heterojunction in its n-state, after a long exposure to $\mathrm{NH}_{3}$ with high humidity levels and it was stabilized in this state. For this ambipolar device, an initial p-state (just after fabrication) was always observed demonstrated by a current decrease under ammonia. After an extended operation under ammonia in humid atmosphere the devices turned into n-state. A p to $\mathrm{n}$ transition could be observed throughout $10 \mathrm{~min}$ - long exposure cycle at $90 \mathrm{ppm} \mathrm{NH}_{3}$, during which the current decreases then increases as a function of time (Fig. S2). Such observations clearly demonstrate the role of $\mathrm{NH}_{3}$ and $\mathrm{H}_{2} \mathrm{O}$ diffusion as a possible trigger in the ambipolar carrier transport regime in $\mathrm{LuPc}_{2} / \mathbf{1}$ device because of their slow diffusion in the sublayer and subsequent $\mathrm{e}$ doping. However, this phenomenon is observed neither with n-type $\mathrm{LuPc}_{2} / \mathbf{2}$ nor with p-type $\mathrm{LuPc}_{2} / \mathbf{3}$ device.
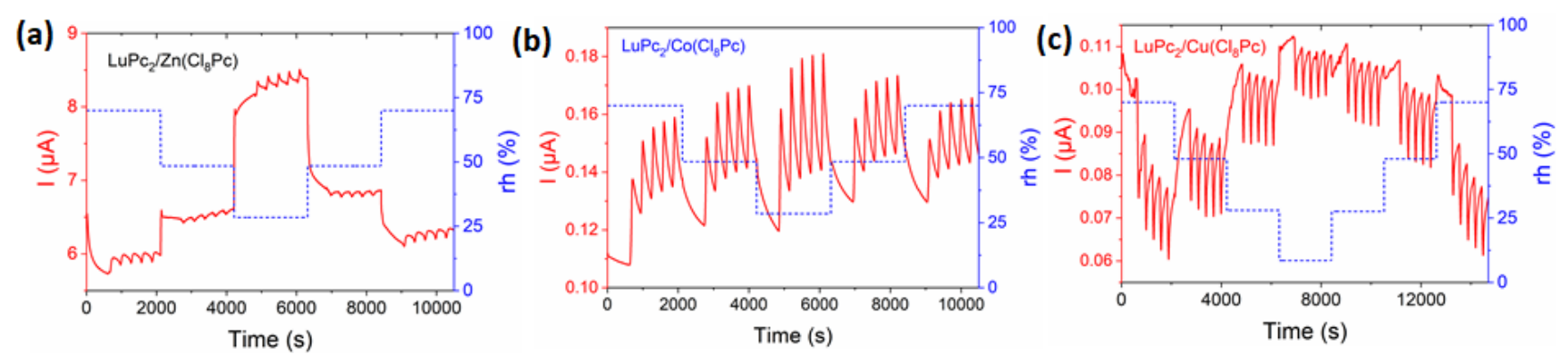

Figure 5. Response to $30 \mathrm{ppm} \mathrm{NH}$ of $\mathrm{LuPc}_{2} / \mathbf{X}$ heterojunctions ( $\mathbf{X}=\mathbf{1}$ (a), $\mathbf{2}$ (b) and $\mathbf{3}$ (c)) for $1 \mathrm{~min} / 4$ min exposure/recovery cycles, at different rh values, at a bias of $1 \mathrm{~V}$.

\section{Quantitative response to ammonia}

The effect of the $\mathrm{NH}_{3}$ concentration was studied during short exposure/recovery cycles (1 min / 4 min), in the range 10-90 ppm (Fig. 6). For $\mathrm{LuPc}_{2} / \mathbf{1}$, in its pstate, the baseline was quasi stable all along the experiment, except at the first exposure period. The RR varies with the $\mathrm{NH}_{3}$ concentration, from $-4.7 \%$ at 10 
ppm to $-6.0 \%$ at $30 \mathrm{ppm}$ and $-9.1 \%$ at $90 \mathrm{ppm}$. In its n-state, the RR increases non-linearly with the $\mathrm{NH}_{3}$ concentration, from $+1.0 \%$ at $10 \mathrm{ppm}$ to $2.35 \%$ at 30 ppm and $+3.7 \%$ at 90 ppm (Fig. 7 ). In the same conditions, the RR values were higher for other chlorinated metallophthalocyanine - based heterojunctions, with a RR value for $\mathrm{LuPc}_{2} / 2$ of $84 \%$ at $90 \mathrm{ppm}$ and $13 \%$ at $10 \mathrm{ppm}$, respectively and of $-27 \%$ and $7 \%$ at 90 and $10 \mathrm{ppm}$, respectively, for $\mathrm{LuPc}_{2} / 3$ (Fig. S3, S4). However, in all cases, the differences between the RR values at 90 and 60 ppm are very small, showing that a saturation occurs in this concentration range.
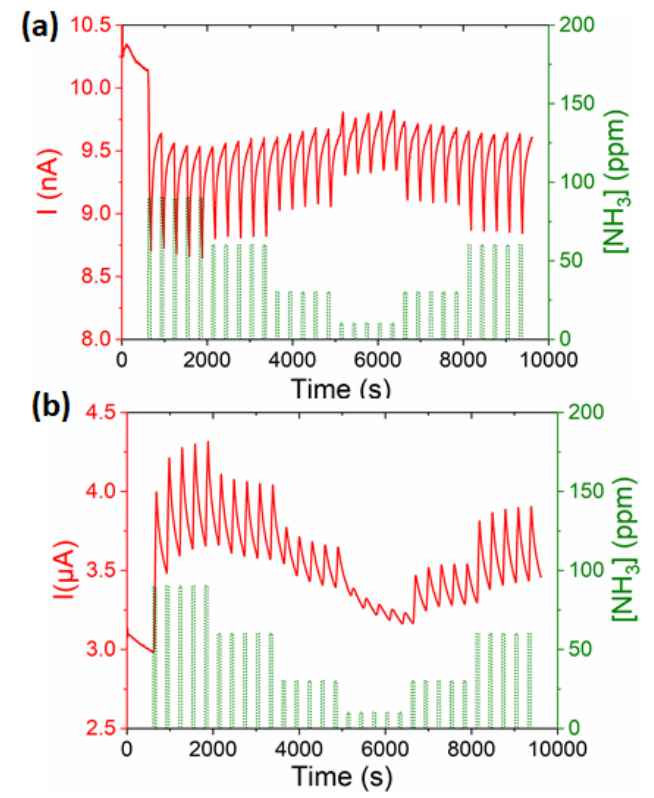

Figure 6. Response to $\mathrm{NH}_{3}$, in the range $10-90 \mathrm{ppm}$, of LuPc$_{2} / \mathbf{1}$ heterojunction in its $\mathrm{p}-(\mathrm{a})$ and n- (b) states, for 1 $\mathrm{min} / 4 \mathrm{~min}$ exposure/recovery cycles, at $30 \% \mathrm{t} \mathrm{rh}$, at a bias of $1 \mathrm{~V}$.

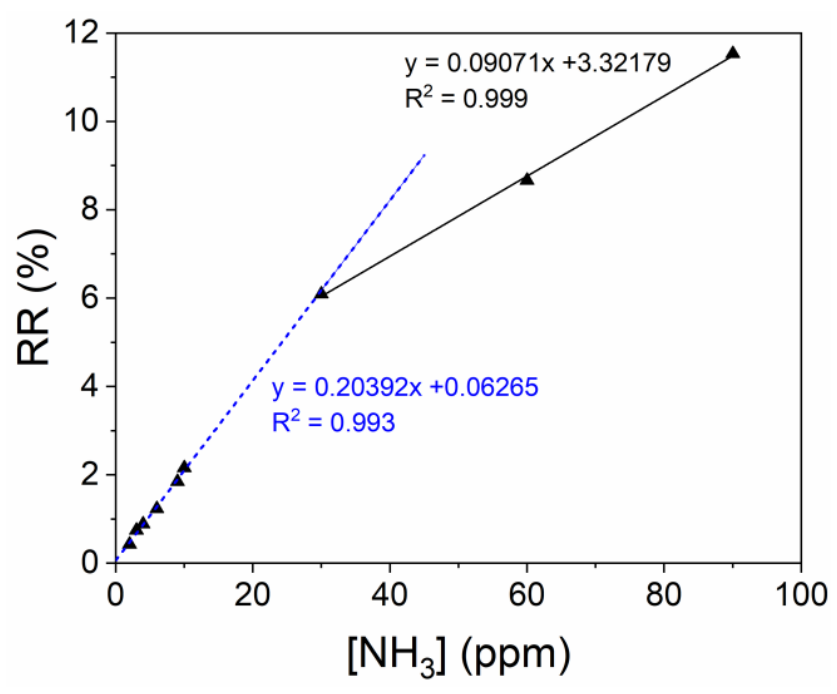

Figure 7. Relative response as a function of the $\mathrm{NH}_{3}$ concentration for the $\mathrm{LuPc}_{2} / \mathbf{1}$ heterojunction in its n-type state.

To evidence this phenomenon, we studied the most sensitive devices at lower $\mathrm{NH}_{3}$ concentrations, in the 1-9 ppm range. Taking into account the baseline current $\mathrm{I}_{0}$ and the noise $N$ at $1 \mathrm{ppm}$, on the I(t) curve, LOD and LOQ can be calculated (Eq. 1 and Eq.2):

$$
\begin{aligned}
& L O D=\frac{3 N}{S * I_{0}} \\
& L O Q=\frac{10 N}{S * I_{0}}
\end{aligned}
$$

By plotting the RR value as a function of the $\mathrm{NH}_{3}$ concentration, two domains are revealed with different sensitivity values (Fig. 7). For $\mathrm{LuPc}_{2} / \mathbf{2}$, the sensitivity, defined as $\mathrm{S}=\Delta \mathrm{RR} / \Delta\left[\mathrm{NH}_{3}\right]$, was $0.90 \% \cdot \mathrm{ppm}^{-1}$ above $10 \mathrm{ppm}$ and $1.48 \%$.ppm ${ }^{-1}$ below $10 \mathrm{ppm} \mathrm{NH}_{3}$, with a LOD of $250 \mathrm{ppb}$ and LOQ of $830 \mathrm{ppb}$, which makes it as good as the best ammonia sensors operating at room temperature. Other reported heterojunctions using $\mathrm{LuPc}_{2}$ as a top layer, by combination with a conducting polymer, exhibited a LOD of 314 $\mathrm{ppb}^{46}$ and $450 \mathrm{ppb}^{47}$, in the same $\mathrm{NH}_{3}$ concentration range, depending on the nature of the polymer and on the geometry of the heterojunction. Elsewhere, conducting polymer - carbon nanotube based resistors exhibit a LOD of $200 \mathrm{ppb}^{48,49}$. $\mathrm{LuPc}_{2} / 3$ is less sensitive, with $\mathrm{S}=-0.14 \% . \mathrm{ppm}^{-1}$ below $10 \mathrm{ppm} \mathrm{NH}_{3}$, with a LOD of $1.18 \mathrm{ppm}$. The $\mathrm{LuPc}_{2} / \mathbf{1}$ heterojunction, in its stabilized $n$-type state, exhibited a $S$ value of $0.09 \%$.ppm $^{-1}$ above $30 \mathrm{ppm}$ and $0.20 \%$.ppm $^{-1}$ below $30 \mathrm{ppm}$, with a LOD of ca. $4.5 \mathrm{ppm}$.

\section{CONCLUSION}

In this study, we showed that the electrical properties of octachloro-metallophthalocyanines depend on the metal center. As expected for monophthalocyanines, their conductivity is low, but they allowed building heterojunction by association with $\mathrm{LuPc}_{2}$. The heterojunction device based on cobalt complex exhibits a n-type behavior whereas the copper complex exhibits a p-type behavior. Interestingly, the device based on zinc complex exhibits a unique feature by showing $\mathrm{p}$ - and n-type carrier transport, which is a typical case of ambipolar devices. In fact, the $\mathrm{LuPc}_{2} / \mathrm{Zn}\left(\mathrm{Cl}_{8} \mathrm{Pc}\right)$ heterojunction behaves as a p-type device, after preparation, with a current decrease under ammonia, but can turn to n-state after extended exposure of $\mathrm{NH}_{3}$ at high rh. Such device polarity transition is attributed to slow diffusion of $\mathrm{NH}_{3}$ and $\mathrm{H}_{2} \mathrm{O}$ in the device sublayer, causing a chemical doping of electron, which changes the electron affinity of $\mathrm{Zn}\left(\mathrm{Cl}_{8} \mathrm{Pc}\right)$. Thus, a role of central metal atom in phthalocyanine is clearly emphasized in modulating the electrical properties of the devices. Moreover, such device characteristics is also correlated with 
the electron hopping between phthalocyanine frontier orbitals at the interface, and subsequent evolution of charges alignment at the heterojunction. All devices studied exhibited high sensitivity to $\mathrm{NH}_{3}$ out of which one based on $\mathrm{Co}\left(\mathrm{Cl}_{8} \mathrm{Pc}\right)$ gives the highest sensitivity of $1.47 \%$. $\mathrm{ppm}^{-1}$, lowest detection limit of $250 \mathrm{ppb}$ and minimum interference of humidity, which makes it among the best ammonia sensors operating in ambient air and at room temperature.

This study allowed us going further in the understanding of the ambipolarity in gas sensors. Likewise a balance that owns only one equilibrium state but an infinity of unbalanced positions, the ambipolarity can be achieved only if the positive and negative mobile charges participate equally to the carrier transport of the device. However, its observation can be prevented by trapping effects and specific interactions with environment. In the present case, the humidity can act as a trigger, and it could be considered as an interfering species. On the contrary, because of their unique feature, such ambipolar sensors would enrich the set of data in sensor arrays, combining them with unipolar sensors. So, the ambipolar behavior can make a conductometric sensor suitable for a multimodal detection. We are currently working on external triggers capable to activate the both states, to take plenty advantages of these unique materials.

\section{MATERIALS AND METHODS}

\section{Materials preparation}

2,3,9,10,16,17,23,24-octachloro-zinc phthalocyanine (1). A mixture of $0.5 \mathrm{~g}(2.72 \mathrm{mmol})$ of 4,5 -dichloro-phthalic anhydride, $0.169 \mathrm{~g}(0.8 \mathrm{mmol})$ of zinc (II) acetate tetrahydrate, $1.4 \mathrm{~g}$ ( $3 \mathrm{mmol})$ of urea and $0.015 \mathrm{~g}$ of ammonium heptamolybdate was refluxed in nitrobenzene for 5 hours. The solid obtained was filtered off, washed successively with ethanol and distilled water, then treated by hot $10 \%$ aqueous $\mathrm{HCl}$ solution, followed by successive washings with toluene, ethanol, methanol and acetone in a soxhlet. $0.288 \mathrm{~g}(0.4 \mathrm{mmol})$ of intense blue color powder was obtained with a yield of $60 \%$. $2,3,9,10,16,17,23,24$-octachloro-cobalt phthalocyanine (2) and 2,3,9,10,16,17,23,24-octachloro-copper phthalocyanine (3) were also synthesized following the similar protocols while using a cobalt (II) acetate tetrahydrate and copper (II) acetate tetrahydrate as a precursor respectively.

Anal. Calcd. for $\mathrm{C}_{32} \mathrm{H}_{8} \mathrm{Cl}_{8} \mathrm{~N}_{8} \mathrm{Zn}$ : C, $45.03 \% ; \mathrm{H}, 0.94 \%$; $\mathrm{N}, 13.13$; found: $\mathrm{C}, 44.93 \%$; $\mathrm{H}, 0.93 \%$;, $13.22 \%$. MALDI-TOF-MS (matrix DIT) $\mathrm{m} / z$ : $853.5466\left(\mathrm{M}^{+}\right.$); calculated for $\mathrm{C}_{32} \mathrm{H}_{8} \mathrm{Cl}_{8} \mathrm{~N}_{8} \mathrm{Zn}$ : 853.7411. FT-IR, $\left(\mathrm{V}, \mathrm{cm}^{-}\right.$ 1): 1598, 1485, 1410, 1378, 1348, 1327, 1289, 1131, 1188, 1085, 1066, 944, 888, 839, 779, 740, 702, 660,
543, 495, 432. UV-vis (DMF): $\lambda_{\max }, \mathrm{nm}(\log \varepsilon): 347$ (Soret band, 5.00), 632 (Q band, 4.94), 708 (sh).

UV-visible, Infra-red and Raman spectroscopies, and mass spectrometry

UV-visible electronic absorption spectra were recorded on a Shimadzu UV-2600 spectrophotometer. FT-IR spectra were recorded on a Bruker Vector 22 spectrometer in transmission mode, using $\mathrm{KBr}$ pellets. Raman spectroscopy was conducted employing a Renishaw inVia Raman microscope with a $473 \mathrm{~nm}$ laser. Mass spectra were recorded on a MALDI (matrix assisted laser desorption ionization) BRUKER Proflex III spectrometer, using 1,8,9-anthracenetriol as a matrix.

\section{Devices and electrical measurements}

Electrical measurements were carried out with Indium Tin Oxide (ITO) interdigitated electrodes (IDE), lithographically patterned on $(1 \times 1) \mathrm{cm}^{2}$ glass substrate and separated by $75 \mu \mathrm{m}$. Thin films of phthalocyanines were prepared by sublimation under secondary vacuum (ca. $10^{-6} \mathrm{mbar}$ ) in a UNIVEX 250 thermal evaporator (Oerlikon, Germany), by heating in a temperature range of $500-550^{\circ} \mathrm{C}$ for the chlorinated phthalocyanines and in the range 400$450^{\circ} \mathrm{C}$ for $\mathrm{LuPc}_{2}$. The deposited thicknesses were 30 $\mathrm{nm}$ for each chlorinated phthalocyanine complex and $50 \mathrm{~nm}$ for $\mathrm{LuPc}_{2}$, as determined by a quartz crystal microbalance during the deposition process. The workbench used for $\mathrm{NH}_{3}$ sensing, at different rh values, was previously described ${ }^{36}$. Synthetic air, ammonia gas, $1000 \mathrm{ppm}$ and $100 \mathrm{ppm}$ in synthetic air, were used from standard cylinders, purchased from Air Liquide (France). The total flow was in the range 0.5-0.55 NL.min ${ }^{-1}$ depending on ammonia concentration and the volume of the test chamber was $8 \mathrm{~cm}^{3}$. Gas sensing experiments were carried out in a dynamic way, alternating $10 \mathrm{~min}$ or $1 \mathrm{~min}$ - long exposure periods with $15 \mathrm{~min}$ or $4 \mathrm{~min}$ - long recovery periods, respectively. All the electrical and sensing measurements were carried out at room temperature $\left(20-24^{\circ} \mathrm{C}\right)$.

\section{ASSOCIATED CONTENT}

\section{Supporting Information}

The Supporting Information is available free of charge on the ACS Publications website.

Molecular structure of different metal phthalocyanines used in the device has been given. The Raman data are given for the octachloro-phthalocyanine - based devices. The transient behavior observed with $\mathrm{LuPc}_{2} / \mathbf{1}$ submitted to $\mathrm{NH}_{3}$ is given and the responses of $\mathrm{LuPc}_{2} / \mathbf{2}$ and $\mathrm{LuPc}_{2} / \mathbf{3}$ as well (PDF).

\section{AUTHOR INFORMATION}




\section{ACKNOWLEDGMENT}

The authors acknowledge the Agence Nationale de la Recherche for funding through the ANR project OUTSMART ANR-2015-CE39-0004-03. Financial support from the European Union (FEDER) and the Conseil Régional de Bourgogne through the FABER and the plan d'actions régional pour l'innovation (PARI CDEA) program is gratefully acknowledged. We acknowledge the Conseil Régional de Bourgogne through the CPER program. This work was also partly supported by the European Union through the PO FEDER-FSE Bourgogne 2014/2020 via the CoMICS program (Chemistry of Molecular Interactions: Catalysis \& Sensors) (A. K.). S. O. is indebted to the Science Institute of Burkina-Faso, for supporting scientific missions in France.

\section{Corresponding Author}

Institut de Chimie Moléculaire de l'Université de Bourgogne (ICMUB), UMR CNRS 6302, Université Bourgogne FrancheComté, 9 av. Alain Savary, 21078 Dijon cedex, France. Tel: +33-380-396-086; E-mail: marcel.bouvet@u-bourgogne.fr Laboratoire de Chimie Moléculaire et de Matériaux, Université Joseph Ki-Zerbo, Ouagadougou, 03 BP 7021, Ouagadougou, Burkina Faso ; E-mail: seydoued2001@yahoo.fr

\section{Author Contributions}

All authors have given approval to the final version of the manuscript.

\section{REFERENCES}

(1) Salzmann, I.; Heimel, G.; Oehzelt, M.; Winkler, S.; Koch, N. Molecular Electrical Doping of Organic Semiconductors: Fundamental Mechanisms and Emerging Dopant Design Rules. Acc. Chem. Res. 2016, 49 (3), 370-378.

(2) Song, R.; Wang, Z.; Zhou, X.; Huang, L.; Chi, L. Gas-Sensing Performance and Operation Mechanism of Organic П-Conjugated Materials. ChemPlusChem 2019, 84 (9), 1222-1234.

(3) Moreno, C.; Pfattner, R.; Mas-Torrent, M.; Puigdollers, J.; Bromley, S. T.; Rovira, C.; Veciana, J.; Alcubilla, R. Evidence of Intrinsic Ambipolar Charge Transport in a High Band Gap Organic Semiconductor. J. Mater. Chem. 2011, 22 (2), 345-348.

(4) Sizov, A. S.; Trul, A. A.; Chekusova, V.; Borshchev, O. V.; Vasiliev, A. A.; Agina, E. V.; Ponomarenko, S. A. Highly Sensitive Air-Stable Easily Processable Gas Sensors Based on LangmuirSchaefer Monolayer Organic Field-Effect Transistors for Multiparametric H2S and NH3 Real-Time Detection. ACS Appl. Mater. Interfaces 2018, 10 (50), 43831-43841.

(5) Parra, V.; Brunet, J.; Pauly, A.; Bouvet, M. Molecular Semiconductor-Doped Insulator (MSDI) Heterojunctions: an Alternative Transducer for Gas Chemosensing. Analyst 2009, 134 (9), 1776-1778.

(6) Feng, Z.; Xie, Y.; Wu, E.; Yu, Y.; Zheng, S.; Zhang, R.; Chen, X.; Sun, C.; Zhang, H.; Pang, W.; Liu, J.; Zhang, D. Enhanced Sensitivity of MoTe2 Chemical Sensor Through Light Illumination. Micromachines 2017, 8 (5), 155.

(7) Chen, H.; Zhang, M.; Bo, R.; Barugkin, C.; Zheng, J.; Ma, Q.; Huang, S.; Ho-Baillie, A. W. Y.; Catchpole, K. R.; Tricoli, A. Superior Self-Powered Room-Temperature Chemical Sensing with Light-Activated Inorganic Halides Perovskites. Small 2018, 14 (7), 1702571.
(8) Zaumseil, J.; Sirringhaus, H. Electron and Ambipolar Transport in Organic Field-Effect Transistors. Chem. Rev. 2007, $107(4), 1296-1323$.

(9) Zhao, Y.; Guo, Y.; Liu, Y. 25th Anniversary Article: Recent Advances in N-Type and Ambipolar Organic Field-Effect Transistors. Adv. Mater. 2013, 25 (38), 5372-5391.

(10) Usta, H.; Facchetti, A.; Marks, T. J. Air-Stable, SolutionProcessable N-Channel and Ambipolar Semiconductors for ThinFilm Transistors Based on the Indenofluorenebis(Dicyanovinylene) Core. J. Am. Chem. Soc. 2008, 130 (27), 8580-8581.

(11) Guillaud, G.; Sadoun, Al, M.; Maitrot, M.; Simon, J.; Bouvet, M. Field-Effect Transistors Based on Intrinsic Molecular Semiconductors. Chem. Phys. Lett. 1990, 167 (6), 503-506.

(12) Dinelli, F.; Capelli, R.; Loi, M. A.; Murgia, M.; Muccini, M.; Facchetti, A.; Marks, T. J. High-Mobility Ambipolar Transport in Organic Light-Emitting Transistors. Adv. Mater. 2006, 18 (11), $1416-1420$

(13) Dodabalapur, A.; Katz, H. E.; Torsi, L.; Haddon, R. C. Organic Field-Effect Bipolar Transistors. Appl. Phys. Lett. 1996, 68 (8), 1108-1110.

(14) Rost, C.; Karg, S.; Riess, W.; Loi, M. A.; Murgia, M.; Muccini, M. Ambipolar Light-Emitting Organic Field-Effect Transistor. Appl. Phys. Lett. 2004, 85 (9), 1613-1615.

(15) Ye, R.; Baba, M.; Mori, K. High-Performance Air-Stable Ambipolar Organic Thin-Film Transistor Based on F16CuPc and CuPc. Jpn J. Appl. phys. 2005, 44 (1), L581-L583.

(16) Wang, J.; WANG, H.; Yan, X.; Huang, H.; Jin, D.; Shi, J.; Tang, Y.; Yan, D. Heterojunction Ambipolar Organic Transistors Fabricated by a Two-Step Vacuum-Deposition Process. Adv. Funct. Mater. 2006, 16 (6), 824-830.

(17) Kong, X.; Dong, Z.; Wu, Y.; Li, X.; Chen, Y.; Jiang, J. High Sensitive Ambipolar Response Towards Oxidizing NO2 and Reducing NH3 Based on Bis(Phthalocyaninato) Europium Semiconductors. Chin. J. Chem. 2016, 34 (10), 975-982.

(18) Liu, S.; Wang, H.; Wang, X.; Li, S.; Liu, H.; Chen, Y.; Li, X Diverse Sensor Responses From Two Functionalized Tris(Phthalocyaninato)Europium Ambipolar Semiconductors Towards Three Oxidative and Reductive Gases. J. Mater. Chem. C 2019, 7 (2), 424-433.

(19) Kong, X.; Zhang, X.; Gao, D.; Qi, D.; Chen, Y.; Jiang, J. AirStable Ambipolar Field-Effect Transistor Based on a SolutionProcessed Octanaphthoxy-Substituted Tris(Phthalocyaninato) Europium Semiconductor with High and Balanced Carrier Mobilities. Chem. Sci. 2015, 6 (3), 1967-1972.

(20) Gao, D.; Zhang, X.; Kong, X.; Chen, Y.; Jiang, J. (TFPP)Eu[Pc(OPh)8]Eu[Pc(OPh)8]/CuPc Two-Component Bilayer Heterojunction-Based Organic Transistors with High Ambipolar Performance. ACS Appl. Mater. Interfaces 2015, 7 (4), 24862493.

(21) Wu, Y.; Ma, P.; Wu, N.; Kong, X.; Bouvet, M.; Li, X.; Chen, Y.; Jiang, J. Two-Step Solution-Processed Two-Component Bilayer Phthalocyaninato Copper-Based Heterojunctions with Interesting Ambipolar Organic Transiting and Ethanol-Sensing Properties. Adv. Mater. Interfaces 2016, 3 (16), 1600253.

(22) Zhao, S.; Kong, X.; Wang, X.; Li, X.; Yang, G.; Chen, Y. Fine-Tuning Intermolecular and Intramolecular Interactions to Build the Films of Tris(Phthalocyaninato) Rare Earth Complexes and Their Comparative Performances in Ambipolar Gas Sensing. IEEE Trans. Electron Dev. 2019, 66 (4), 1930-1936.

(23) Lu, G.; Kong, X.; Wang, C.; Zhao, L.; Qi, D.; Jiang, Y.; Zhao, S.; Chen, Y.; Jiang, J. Optimizing the Gas Sensing Properties of Sandwich-Type Phthalocyaninato Europium Complex Through Extending the Conjugated Framework. Dyes Pigments 2019, 161, 240-246.

(24) Bouvet, M.; Xiong, H.; Parra, V. Molecular Semiconductor-Doped Insulator (MSDI) Heterojunctions: Oligothiophene/Bisphtalocyanine (LuPc2) and Perylene/Bisphthalocyanine as New Structures for Gas Sensing. Sens. Actuators: B. Chem. 2010, 145 (1), 501-506. 
(25) Wannebroucq, A.; Ouedraogo, S.; Meunier-Prest, R.; Suisse, J.-M.; Bayo, M.; Bouvet, M. On the Interest of Ambipolar Materials for Gas Sensing. Sens. Actuators: B. Chem. 2018, 258, 657-664.

(26) Dutta, S.; Lewis, S. D.; Dodabalapur, A. Hybrid Organic/Inorganic Ambipolar Thin Film Transistor Chemical Sensor. Appl. Phys. Lett. 2011, 98 (21), 213504.

(27) Wang, B.; Huynh, T.-P.; Wu, W.; Hayek, N.; Do, T. T.; Cancilla, J. C.; Torrecilla, J. S.; Nahid, M. M.; Colwell, J. M.; Gazit, O. M.; Puniredd, S. R.; McNeill, C. R.; Sonar, P.; Haick, H. A Highly Sensitive Diketopyrrolopyrrole-Based Ambipolar Transistor for Selective Detection and Discrimination of Xylene Isomers. Adv. Mater. 2016, 28 (21), 4012-4018.

(28) Sugimoto, H.; Higashi, T.; Mori, M. Preparation and Characterization of Some Rare-Earth Complexes of the Phthalocyanine Radical. Chem. Lett. 1983, 12 (8), 1167-1170.

(29) Markovitsi, D.; Tran-Thi, T.-H.; Even, R.; Simon, J. Near Infrared Absorption Spectra of Lanthanide Bis-Phthalocyanines. Chem. Phys. Lett. 1987, 137 (2), 107-112.

(30) Bao, M.; Bian, Y.; Rintoul, L.; Wang, R.; Arnold, D. P.; Ma, C.; Jiang, J. Vibrational Spectroscopy of Phthalocyanine and Naphthalocyanine in Sandwich-Type (Na)Phthalocyaninato and Porphyrinato Rare Earth Complexes. Vibr. Spectrosc. 2004, 34 (2), 283-291.

(31) Bouvet, M.; Mateos, M.; Wannebroucq, A.; Navarrete, E.; Llobet, E. Tungsten Oxide - Lutetium Bisphthalocyanine N-P-N Hetero-Junction: From Nanomaterials to a New Transducer for Chemo-Sensing. J. Mater. Chem. C 2019, 7, 6448-6455.

(32) Wannebroucq, A.; Gruntz, G.; Suisse, J.-M.; Nicolas, Y.; Meunier-Prest, R.; Mateos, M.; Toupance, T.; Bouvet, M. New NType Molecular Semiconductor-Doped Insulator (MSDI) Heterojunctions Combining a Triphenodioxazine (TPDO) and the Lutetium Bisphthalocyanine (LuPc2) for Ammonia Sensing. Sens. Actuators: B. Chem. 2018, 255 (1), 1694-1700.

(33) Mateos, M.; Meunier-Prest, R.; Suisse, J.-M.; Bouvet, M. Modulation of the Organic Heterojunction Behavior, From Electrografting to Enhanced Sensing Properties. Sens. Actuators: B. Chem. 2019, 299, 126968.

(34) Meyer, J. P.; Schlettwein, D. Influence of Central Metal and Ligand System on Conduction Type and Charge Carrier Transport in Phthalocyanine Thin Films. Adv. Mater. Opt. Electr. 1996, 6 (5-6), 239-244.

(35) Liao, M.-S.; Scheiner, S. Electronic Structure and Bonding in Metal Phthalocyanines, Metal=Fe, Co, Ni, Cu, Zn, Mg. J. Chem. Phys. 2001, 114 (22), 9780-9791.

(36) Bouvet, M.; Gaudillat, P.; Kumar, A.; Sauerwald, T.; Schüler, M.; Schütze, A.; Suisse, J.-M. Revisiting the Electronic Properties of Molecular Semiconductor - Doped Insulator (MSDI) Heterojunctions Through Impedance and Chemosensing Studies. Org. Electron. 2015, 26, 345-354.
(37) Brinkmann, H.; Kelting, C.; Makarov, S.; Tsaryova, O.; Schnurpfeil, G.; Wöhrle, D.; Schlettwein, D. Fluorinated Phthalocyanines as Molecular Semiconductor Thin Films. Phys. Status Solidi A 2008, 205 (3), 409-420.

(38) Scudiero, L.; K W Hipps, A.; Barlow, D. E. A Self-Organized Two-Dimensional Bimolecular Structure. J. Phys. Chem. B 2003, 107 (13), 2903-2909.

(39) Mayer, T.; Weiler, U.; Kelting, C.; Schlettwein, D.; Makarov, S.; Wöhrle, D.; Abdallah, O.; Kunst, M.; Jaegermann, W. Silicon-Organic Pigment Material Hybrids for Photovoltaic Application. Solar Energy Materials and Solar Cells 2007, 91 (20), 1873-1886.

(40) Murdey, R.; Sato, N.; Bouvet, M. Frontier Electronic Structures in Fluorinated Copper Phthalocyanine Thin Films Studied Using Ultraviolet and Inverse Photoemission Spectroscopies. Mol. Cryst. Liq. Cryst. 2006, 455 (1), 211-218.

(41) Amsalem, P.; Giovanelli, L.; Themlin, J. M.; Koudia, M.; Abel, M.; Oison, V.; Ksari, Y.; Mossoyan, M.; Porte, L. Interface Formation and Growth of a Thin Film of ZnPcCl8/Ag(1 1 1) Studied by Photoelectron Spectroscopy. Surface Science 2007, 601 (18), 4185-4188.

(42) Bouvet, M.; Simon, J. Electrical Properties of Rare Earth Bisphthalocyanine and Bisnaphthalocyanine Complexes. Chem. Phys. Lett. 1990, 172 (3-4), 299-302.

(43) Zhu, L.; Tang, H.; Harima, Y.; Kunugi, Y.; Yamashita, K.; Ohshita, J.; Kunai, A. A Relationship Between Driving Voltage and the Highest Occupied Molecular Orbital Level of Hole-Transporting Metallophthalocyanine Layer for Organic Electroluminescence Devices. Thin Solid Films 2001, 396 (1-2), 214-219.

(44) Wang, H.; Yan, D. Organic Heterostructures in Organic Field-Effect Transistors. NPG Asia Mater. 2010, 2 (2), 69-78.

(45) Matsuguchi, M.; Okamoto, A.; Sakai, Y. Effect of Humidity on NH3 Gas Sensitivity of Polyaniline Blend Films. Sens. Actuators: B. Chem. 2003, 94 (1), 46-52.

(46) Mateos, M.; Tchangaï, M.-D.; Meunier-Prest, R.; Heintz, 0.; Herbst, F.; Suisse, J.-M.; Bouvet, M. Low Conductive Electrodeposited Poly(2,5-Dimethoxyaniline) as a Key Material in a Double Lateral Heterojunction, for Sub-Ppm Ammonia Sensing in Humid Atmosphere. ACS Sens. 2019, 4 (3), 740-747.

(47) Mateos, M.; Meunier-Prest, R.; Heintz, O.; Herbst, F.; Suisse, J.-M. Comprehensive Study of Poly(2,3,5,6-Tetrafluoroaniline): From Electrosynthesis to Heterojunctions and Ammonia Sensing. ACS Appl. Mater. Interfaces 2018, 10, 19974-19986.

(48) Chang, Q.; Zhao, K.; Chen, X.; Li, M.; Liu, J. Preparation of Gold/Polyaniline/Multiwall Carbon Nanotube Nanocomposites and Application in Ammonia Gas Detection. J. Mater. Sci. 2008, 43 (17), 5861-5866.

(49) Jian, J.; Guo, X.; Lin, L.; Cai, Q.; Cheng, J.; Li, J. Gas-Sensing Characteristics of Dielectrophoretically Assembled Composite Film of Oxygen Plasma-Treated SWCNTs and PEDOT/PSS Polymer. Sens. Actuators: B. Chem. 2013, 178, 279-288. 


\section{SUPPORTING INFORMATION}
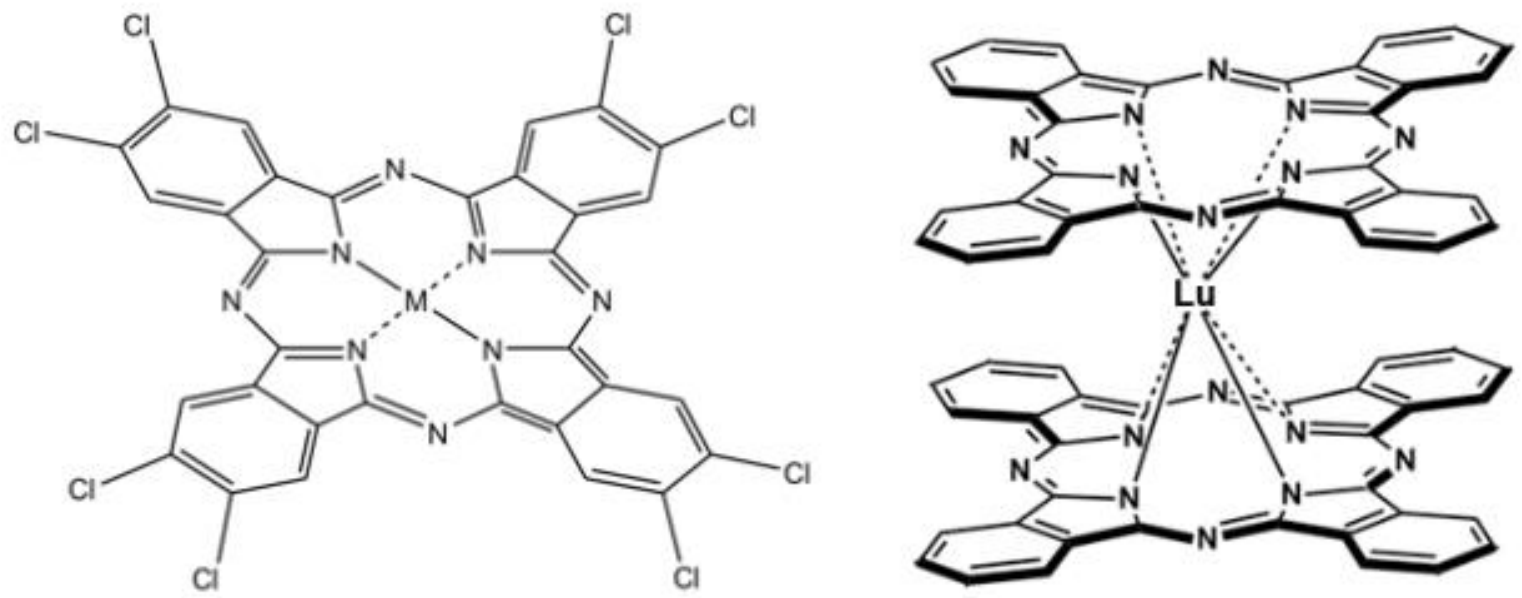

Figure S1. Structure of octachloro metallophthalocyanines (left) and lutetium bisphthalocyanine (right). 
Table 1. Raman data (in $\mathrm{cm}^{1}$ ) of $\mathrm{LuPc}_{2} / \mathbf{1}, \mathrm{LuPc}_{2} / \mathbf{2}$, and $\mathrm{LuPc}_{2} / \mathbf{3}$ devices compared to these of each product as powder, and their attribution (s: strong, m: medium and w: weak).

\begin{tabular}{|c|c|c|c|c|c|c|c|}
\hline $\begin{array}{l}\mathrm{Zn}\left(\mathrm{Cl}_{8} \mathrm{Pc}\right) \\
\text { powder }\end{array}$ & $\begin{array}{l}\mathrm{LuPc}_{2} / \mathbf{1} \\
\mathrm{MSDI}\end{array}$ & $\begin{array}{c}\text { LuPc2 } \\
\text { powder }\end{array}$ & $\begin{array}{c}\mathrm{Co}\left(\mathrm{Cl}_{8} \mathrm{Pc}\right) \\
\text { powder }\end{array}$ & $\begin{array}{c}\mathrm{LuPc}_{2} / 2 \\
\mathrm{MSDI}\end{array}$ & $\begin{array}{c}\mathrm{Cu}\left(\mathrm{Cl}_{8} \mathrm{Pc}\right) \\
\text { powder }\end{array}$ & $\begin{array}{c}\mathrm{LuPc}_{2} / 3 \\
\mathrm{MSDI}\end{array}$ & Assignment \\
\hline \multirow[t]{3}{*}{547 w } & $550,565 \mathrm{w}$ & $548 w$ & $549 w$ & $556,565 \mathrm{w}$ & $547 w$ & $547 w$ & Pc breathing \\
\hline & $578 \mathrm{w}$ & $578 w$ & & $579 w$ & & $576 \mathrm{w}$ & Pc breathing \\
\hline & & & & & & & Pc breathing \\
\hline $660 \mathrm{~S}$ & $659 w$ & & $663 \mathrm{~S}$ & $663 w$ & $661 \mathrm{~S}$ & $659 w$ & Pc breathing \\
\hline $685 w$ & $682 \mathrm{~S}$ & $682 \mathrm{~S}$ & $690 \mathrm{~m}$ & $682 \mathrm{~m}$ & $689 w$ & $680 \mathrm{~m}$ & Pc breathing \\
\hline \multirow{2}{*}{$749 w$} & $743 \mathrm{~m}$ & $735 \mathrm{~m}$ & $751 \mathrm{w}$ & $742 w$ & $748 w$ & $741 w$ & CH wagging \\
\hline & $783 \mathrm{~m}$ & $781 \mathrm{~m}$ & & $783 w$ & & $781 \mathrm{w}$ & $\mathrm{C}=\mathrm{N}$ aza Stretching \\
\hline $812 w$ & $815 w$ & & $817 w$ & $819 w$ & $812 w$ & $812 w$ & Pc breathing \\
\hline \multirow[t]{3}{*}{$861 \mathrm{w}$} & $861 \mathrm{w}$ & & $868 \mathrm{~m}$ & $867 w$ & $864 \mathrm{w}$ & $864 \mathrm{w}$ & \\
\hline & $1007 \mathrm{w}$ & $1012 \mathrm{w}$ & & $1008 \mathrm{w}$ & & $1007 \mathrm{w}$ & $\mathrm{CH}$ bending \\
\hline & & $1033 \mathrm{w}$ & & & & & $\mathrm{CH}$ bending \\
\hline $1046 \mathrm{~m}$ & $1048 w$ & & $1056 \mathrm{~m}$ & $1055 \mathrm{w}$ & $1051 \mathrm{~m}$ & $1051 \mathrm{w}$ & CH bending \\
\hline \multirow[t]{3}{*}{$1092 \mathrm{w}$} & $1104 \mathrm{w}$ & $1104 \mathrm{w}$ & $1091 \mathrm{w}$ & $1105 \mathrm{w}$ & $1093 \mathrm{w}$ & $1104 \mathrm{w}$ & $\mathrm{CH}$ bending \\
\hline & $1122 \mathrm{~S}$ & $1122 \mathrm{~S}$ & & $1122 \mathrm{~S}$ & & $1121 \mathrm{~S}$ & CH bending \\
\hline & $1158 \mathrm{w}$ & $1147 \mathrm{w}$ & & $1159 \mathrm{w}$ & & $1158 \mathrm{~S}$ & pyrrole breathing \\
\hline $1167 \mathrm{~m}$ & $1176 \mathrm{~S}$ & $1177 \mathrm{~m}$ & $1174 \mathrm{~m}$ & $1175 \mathrm{~m}$ & $1169 \mathrm{~m}$ & $1175 \mathrm{~S}$ & $\mathrm{CH}$ bending \\
\hline $1191 \mathrm{~m}$ & & & $1188 \mathrm{~m}$ & & $1182 \mathrm{~m}$ & & $\mathrm{CH}$ bending \\
\hline $1210 \mathrm{~m}$ & $1210 \mathrm{w}$ & $1217 \mathrm{w}$ & $1209 \mathrm{~S}$ & $1211 \mathrm{w}$ & $1207 \mathrm{~m}$ & $1206 \mathrm{w}$ & $\mathrm{CH}$ bending \\
\hline \multirow[t]{2}{*}{$1319 \mathrm{w}$} & $1301 \mathrm{w}$ & $1303 w$ & $1304 \mathrm{~m}$ & $1304 \mathrm{w}$ & $1303 w$ & $1302 \mathrm{w}$ & $\mathrm{CH}$ bending \\
\hline & $1333 \mathrm{w}$ & $1333 \mathrm{w}$ & & $1336 \mathrm{w}$ & & $1335 \mathrm{w}$ & $\begin{array}{l}\mathrm{C}=\mathrm{C} \text { pyrrole and } \\
\text { benzene stretching }\end{array}$ \\
\hline $1394 \mathrm{~S}$ & $1394 \mathrm{~m}$ & & $1386 \mathrm{~S}$ & $1387 \mathrm{~m}$ & $\begin{array}{c}1367 \mathrm{~m}, \\
1392 \mathrm{~S}\end{array}$ & & \\
\hline \multirow[t]{3}{*}{$1410 w$} & $1409 \mathrm{~S}$ & $1408 \mathrm{~S}$ & & $1409 \mathrm{~S}$ & & $1408 \mathrm{~S}$ & isoindole stretching \\
\hline & & & & $1429 \mathrm{w}$ & & $1426 \mathrm{w}$ & isoindole stretching \\
\hline & & & & & $1490 \mathrm{w}$ & & $\mathrm{C}=\mathrm{C}$ pyrrole stretchin \\
\hline \multirow[t]{2}{*}{$1510 \mathrm{~S}$} & $1512 \mathrm{~S}$ & $1512 \mathrm{~S}$ & & $1513 \mathrm{~m}$ & & $1513 \mathrm{~S}$ & $\begin{array}{l}\text { coupling of pyrrole } \\
\text { and aza stretching }\end{array}$ \\
\hline & & & $1547 \mathrm{~S}$ & $1546 \mathrm{~m}$ & $1529 \mathrm{~S}$ & $1531 \mathrm{~S}$ & benzene stretching \\
\hline $1571 \mathrm{~S}$ & $1574 \mathrm{w}$ & & $1584 \mathrm{~S}$ & & $1577 \mathrm{~S}$ & $1581 \mathrm{~m}$ & benzene stretching \\
\hline $1604 \mathrm{~m}$ & $1599 \mathrm{~S}$ & $1601 \mathrm{~S}$ & $1607 \mathrm{~S}$ & $1601 \mathrm{~S}$ & $1603 \mathrm{~S}$ & $1600 \mathrm{~S}$ & benzene stretching \\
\hline
\end{tabular}




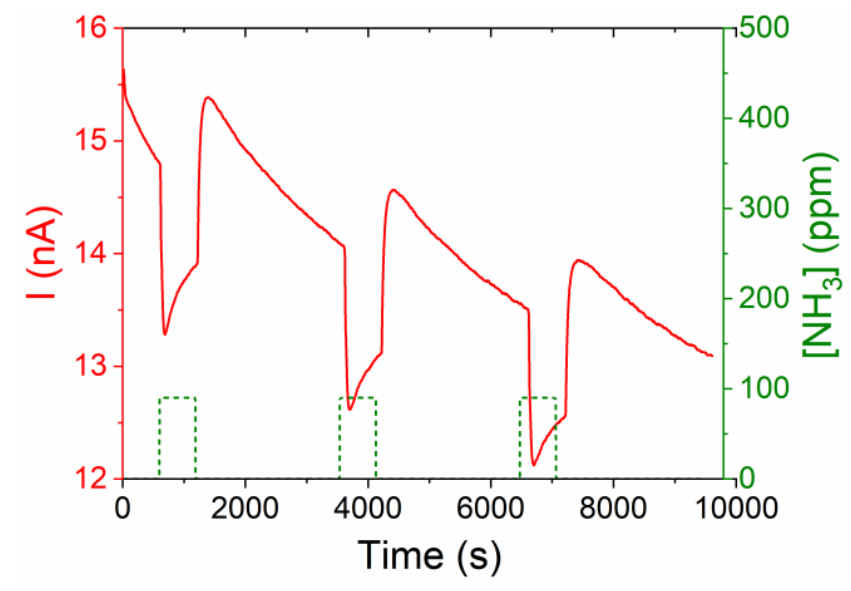

Figure S2. Example of $\mathrm{p}$ to $\mathrm{n}$ transition observed with $\mathrm{LuPc}_{2} / \mathbf{1}$ submitted to $90 \mathrm{ppm} \mathrm{NH}_{3}$, at $30 \%$ rh, with a bias of $1 \mathrm{~V}$.
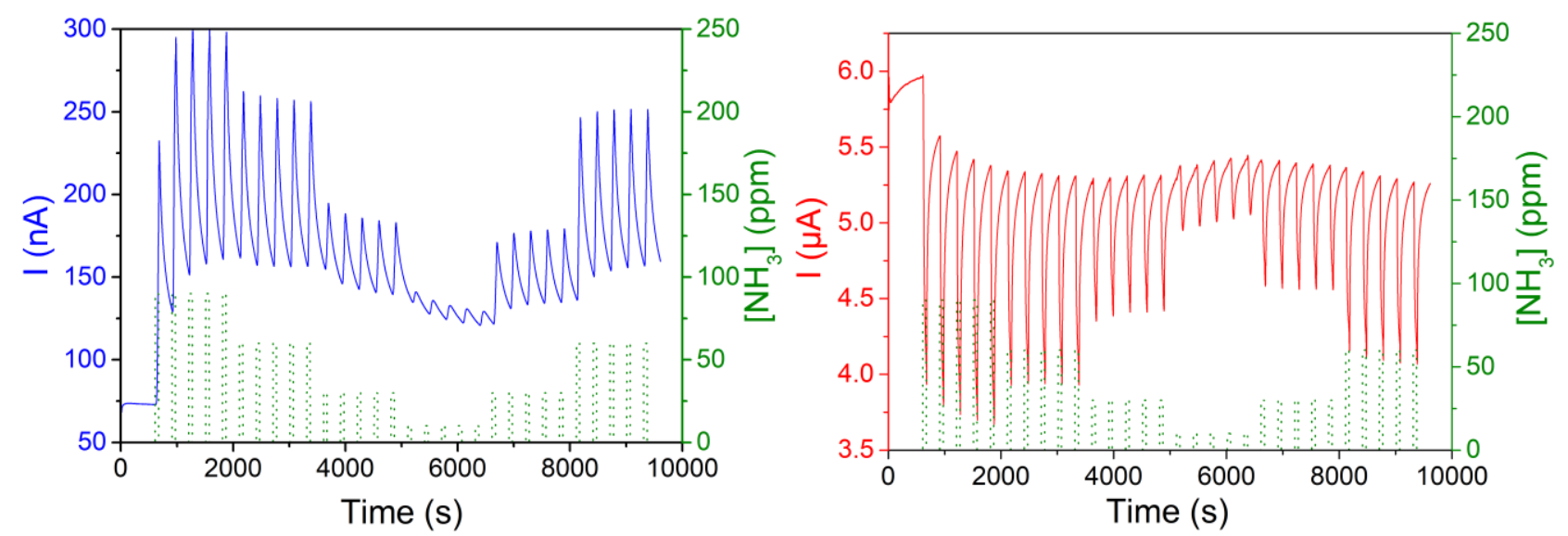

Figure S3. Response to $\mathrm{NH}_{3}$, in the range 10-90 ppm, of $\mathrm{LuPc}_{2} / 2$ (left) and $\mathrm{LuPc}_{2} / 3$ (right) heterojunctions, for 1 min/4 min exposure/recovery cycles, at $30 \% \mathrm{t}$ rh, at a bias of $1 \mathrm{~V}$.

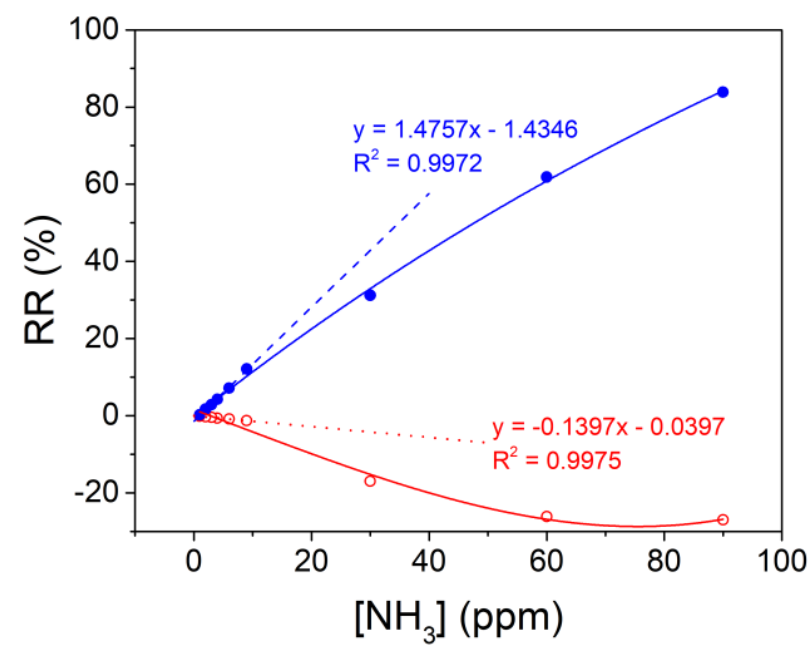

Figure S4. Relative response as a function of the $\mathrm{NH}_{3}$ concentration for $\mathrm{LuPc}_{2} / 2(\bullet)$ and $\mathrm{LuPc}_{2} / 3(\mathrm{O})$ heterojunctions. The linear fits at low concentrations are given. 